\title{
Effect of Conventional Phototherapy on Platelet Count in Full Term and Preterm Neonates with Indirect Hyperbilirubinemia
}

\author{
A.A.Abou Amer ${ }^{1}$, A.E.Diab ${ }^{1}$, O.S.El-Shimi ${ }^{2}$ and M.M.Abd El-Hamied ${ }^{1}$ \\ ${ }^{1}$ Pediatric Dept., Faculty of Medicine, Benha Univ., Benha, Egypt \\ ${ }^{2}$ Clinical and Chemical Pathology Dept., Faculty of Medicine, Benha Univ., Benha, Egypt
}

E-Mail:mohamed@gmail.com

\begin{abstract}
Phototherapy plays a significant role in prevention and treatment of hyperbilirubinemia. Side effect of phototherapy on platelet count has not been described in detail. A few creators watched diminished platelet includes in neonates presented to photograph treatment. Our plan to assess the impact of ordinary phototherapy on platelet include in neonates with roundabout hyperbilirubinemia in benha college medical clinic. This examination comprised of 100 back to back neonates with hyperbilirubinemia both preterm and full term included conceded in neonatal emergency unit phototherapy, in the age gathering of 2 days to 28 days with negative direct Coomb's test and negative $\mathrm{C}$ - responsive protein., Serum bilirubin and CBC with Platelet tally was performed before beginning PT, Twenty four hours (24Hrs) after PT and forty eight hours (48 Hrs) after phototherapy or at stopping of phototherapy whichever was before. Information examination was performed utilizing the product SPSS (Statistical Package for the Social Sciences) variant 20. The aftereffects of this examination demonstrated A sum of $100(100 \%)$ neonates with roundabout hyperbilirubinemia were tried out the investigation, of which $52(52 \%)$ were male and $48(48 \%)$ were female. $62(62 \%)$ were Full term 38(38\%) were preterm. Platelet include in preterm and full term neonates was fundamentally diminished after $24 \mathrm{~h}$ and $48 \mathrm{~h}$ of beginning phototherapy when contrasted and platelet depend on affirmation $(\mathrm{P}=0.001 \mathrm{each})$. At the point when whole examination populace was concentrated in general, it was discovered that Platelet tally was fundamentally diminished after $24 \mathrm{hrs}$ and $48 \mathrm{hrs}$ of beginning phototherapy when contrasted and platelet depend on affirmation $(\mathrm{P}<0.001$ each), and platelet tally at $24 \mathrm{~h}$ subsequent to beginning phototherapy was essentially diminished than $48 \mathrm{~h}$ in the wake of beginning phototherapy ( $\mathrm{P}$ $<0.001$ ).In end; phototherapy in infants with circuitous hyperbilirubinemia prompts decline in platelet include both in full term and preterm babies. The diminishing in platelet tally after phototherapy is transient. This lessening in platelet check is progressively huge following 24 hours of phototherapy.
\end{abstract}

Keywords: Phototherapy, Hyperbilirubinemia, Platelet count.

\section{Introduction}

Neonatal jaundice is one of the most happening clinical issues saw during the main seven day stretch of life influencing about $60 \%$ of term and $80 \%$ of preterm neonates. Pathophysiological premise of the jaundice is the equivalent in all neonates, however preterm neonates are at a higher danger of creating jaundice. High bilirubin level may cause neurological disability even in term neonates. Around $5-10 \%$ of them have clinically critical hyperbilirubinemia [1]. Phototherapy is the utilization of noticeable light for the treatment of hyperbilirubinemia in the infant. This moderately is a typical treatment that brings down the serum bilirubin level by changing bilirubin into water-solvent isomers that can be killed without conjugation in the liver. The portion of phototherapy is a key factor in how rapidly it functions. Portion, thusly, is dictated by the frequency of the light, the power of the light (irradiance), the separation between the light and the child, and the body surface territory presented to the light. Industrially accessible phototherapy frameworks incorporate those that convey light through bright light bulbs, halogen quartz lights, light-emanating diodes, and fiber-optic sleeping pads. Guardian duties incorporate guaranteeing successful irradiance conveyance, augmenting skin presentation, giving eye security and eye care, cautious regard for thermoregulation, keeping up sufficient hydration, advancing disposal, and supporting guardian newborn child cooperation [2]. Neonatal phototherapy, a noninvasive, effectively accessible treatment, has been utilized for the treatment of neonatal jaundice for the greater part a century around the world. Its proficiency in diminishing plasma bilirubin focus is all around archived, and prompts decline requirement for trade transfusion extraordinarily. It is commonly acknowledged that the reactions of neonatal phototherapy are not genuine and appear to be very much controlled [3]. Thrombocytopenia - platelet check under $(150 \times 109 / \mathrm{L})$ is one of the most well-known hematological issues in neonates, especially the individuals who are preterm and debilitated. Early thrombocytopenia happens inside $72 \mathrm{~h}$ of birth, the most widely recognized reason is diminished platelet creation auxiliary to intrauterine development limitation and additionally maternal hypertension. Then again, the most well-known reasons for thrombocytopenia emerging after the initial $72 \mathrm{~h}$ of life, both in preterm and term newborn children, are sepsis and necrotizing enterocolitis. The most significant reason for extreme thrombocytopenia is neonatal alloimmune thrombocytopenia, as determination can be deferred and demise or long haul incapacity because of intracranial discharge may happen. Platelet transfusion is the pillar of treatment for serious thrombocytopenia [4].

\section{Subjects and methods}

\subsection{Subjects}

This investigation was performed on 100 back to back preterm and full-term neonates conceded in the Neonatal Intensive Care Unit (NICU) at Benha 
University Hospitals to get phototherapy. They were conveyed by vaginal and Cesarean Section (CS). The impact of customary phototherapy on platelets include was resolved in the considered neonates.

Clearly sound neonates matured somewhere in the range of 2 and 28 days either full term or preterm were remembered for the examination when they had aberrant hyperbilirubinemia where the utilization of phototherapy was begun by the rules of American Academy of Pediatrics, Negative Direct Coomb's test and Cresponsive protein (CRP).Neonates were rejected from this investigation if the standard platelet check was under $150 \times 103 / \mathrm{mm} 3$, Neonates were readmitted for hyperbilirubinemia and in the event that they had comorbidities like (ABO or $\mathrm{RH}$ contradictions, direct hyperbilirubinemia, sepsis, birth asphyxia, inborn inconsistencies and hostile to platelet drugs given to mother or baby). The study convention was affirmed by the neighborhood Ethical Scientific Committee of Faculty of Medicine - Benha University. Composed educated assent was acquired from guardians before enlistment in the investigation.

\subsection{Methods}

Survey technique, mother's antenatal consideration document and infant assessment were utilized to acquire the necessary information. Subsequent to applying both consideration and prohibition models, icteric neonates were exposed to full history taking including maternal age and financial status, maternal clinical history of any intense or incessant disease previously or during pregnancy maternal history of medication admission, maternal obstetric history including equality, gravidity, premature births, and method of conveyance, maternal blood gathering and past transfusion, antenatal history of contemplated cases including method of conveyance, any perinatal occasion, conveyance information as length of work, span of break of films, , amniotic liquid status, , neonatal assessment in the conveyance room, postnatal history including postnatal age, time of beginning of jaundice, grumblings other than jaundice, kind of milk (bosom, recipe or both)and history of jaundice and any side effects saw by the mother or parental figures.

Clinical assessment including general assessment as shade of the infant like jaundice, paleness, cyanosis, plethoric or meconium recolored,outward presentation , surface of the skin and nails. Essential signs as temperature, beat and respiratory rate .Anthropometric estimations including body weight, length, head and chest periphery. Evaluation of the movement of the infant as being dynamic, feeble or flabby. Neighborhood assessment of head for size, condition of the fontanels and scalp and skull stitches, assessment of the head included assessment of mouth, eyes, hair, and the nose for intrinsic abnormalities. Framework survey including cardiovascular assessment for auscultation of the heart sounds and location of any intrinsic heart ailments or mumbles, chest assessment for indications of respiratory pain or inherent mutation, stomach assessment for obvious peristalsis, stomach divider deserts ,any organomegaly and neurological assessment to preclude any clear of bilirubin encephalopathy including neonatal reflexes, action, condition of awareness and any strange developments.

Standard routine research facility examinations were done to every neonate on confirmation including :( Complete Blood Count (CBC) utilizing computerized cell counter with fringe smear, Serum absolute and circuitous bilirubin-receptive protein (CRP), Direct Coomb's test and $\mathrm{ABO}$ and $\mathrm{Rh}$ blood group).After neonatal assessment, phototherapy was begun dependent on all out serum bilirubin level. Signs of phototherapy were according to rules of National Neonatology Forum 2010. Serum bilirubin and CBC with platelets check were performed 24 and 48 hours after phototherapy or at stopping of phototherapy whichever was before. The platelet tally before beginning phototherapy was considered as the control an incentive for particular neonate.

\subsection{Statistical methods}

Data analysis was performed using the software SPSS (Statistical Package for the Social Sciences) version 20. Quantitative variables were described using their means and standard deviations. KolmogorovSmirnov (distribution-type) and Levene (homogeneity of variances) tests were used to verify assumptions for use in parametric tests. Mann whitney test (used with nonnormally distributed data) was used to compare medians of two groups. To compare one parameter within the same group, Wilcoxon signed rank test (for two points of time) and Friedman test (if more than two points of time). The level statistical significance was set at 5\% $(\mathrm{P}<0.05)$. Highly significant difference was present if $(\mathrm{p} \leq 0.001)$.

\section{Results}

This study was performed on 100 consecutive preterm and full-term neonates admitted in the Neonatal Intensive Care Unit (NICU) at Benha University Hospitals to receive phototherapy. The study included 52 male and 48 female neonates. They were $38 \%$ preterm and $62 \%$ full-term. Platelet count was significantly decreased after $24 \mathrm{hrs}$ and $48 \mathrm{hrs}$ of starting phototherapy when compared with platelet count on admission ( $\mathrm{P}$ $<0.001$ each). Moreover, platelet count showed a significant variability when compared at the three time points $(\mathrm{P}<0.001)$ and also between platelet count after 24 and 48 hours Table (1) Fig (1). Platelet count was significantly decreased in preterm neonates after $24 \mathrm{hrs}$ and $48 \mathrm{hrs}$ of starting phototherapy when compared with platelet count on admission ( $\mathrm{P}=0.001$ each). Moreover, platelet count showed significant variability in preterm neonates when compared at the three time points ( $\mathrm{P}$ <0.001) Table (2) Fig (2). Platelet count was significantly decreased in full term neonates after $24 \mathrm{hrs}$ and $48 \mathrm{hrs}$ of starting phototherapy when compared with platelet count on admission ( $\mathrm{P}=0.001$ each). Moreover, platelet count showed significant variability in full term neonates when compared at the three time points $(\mathrm{P}$ 
<0.001) Table (3) Fig (3). Platelet count was significantly decreased after $24 \mathrm{hrs}$ and $48 \mathrm{hrs}$ of starting phototherapy when compared with platelet count on admission in preterm and full term neonates $(\mathrm{P}=0.001$ each) Table (4) Fig (4) There were no significant differences in platelet count regarding gender either before phototherapy or $24 \mathrm{hr}$ or $48 \mathrm{hr}$ hours after phototherapy Table (5) Fig (5).
Among the studied subjects; $8(21 \%)$ of preterm neonates and $11(17.7 \%)$ of full term neonates had thrombocytopenia (platelet count $<150 \times 10^{3} / \mathrm{mm}^{3}$ ) after 24 hours of starting phototherapy. While, after 48 hours of starting phototherapy $8(21 \%)$ of preterm neonates and $15(24.2 \%)$ of full term neonates had thrombocytopenia Table (6). Table (7).

Table (1) Change in platelet count among the studied patients over time.

\begin{tabular}{|c|c|c|c|c|}
\hline Platelet count $\left(\times 10^{3} / \mathrm{mm}^{3}\right)$ & Mean \pm SD & Median & Range & $\mathbf{P}^{*}$ \\
\hline On admission & $295.86 \pm 103.33$ & 277 & $150-541$ & -- \\
\hline After 24 hours & $249.99 \pm 98.31$ & 245.5 & $45-479$ & $<0.001$ \\
\hline After 48 hours & $262.79 \pm 111.05$ & 251.5 & $95-511$ & $<0.001$ \\
\hline Friedman test & & 134.16 & & \\
\hline $\mathrm{P}$ & & $<0.001$ & & \\
\hline
\end{tabular}

*Wilcoxon signed rank test

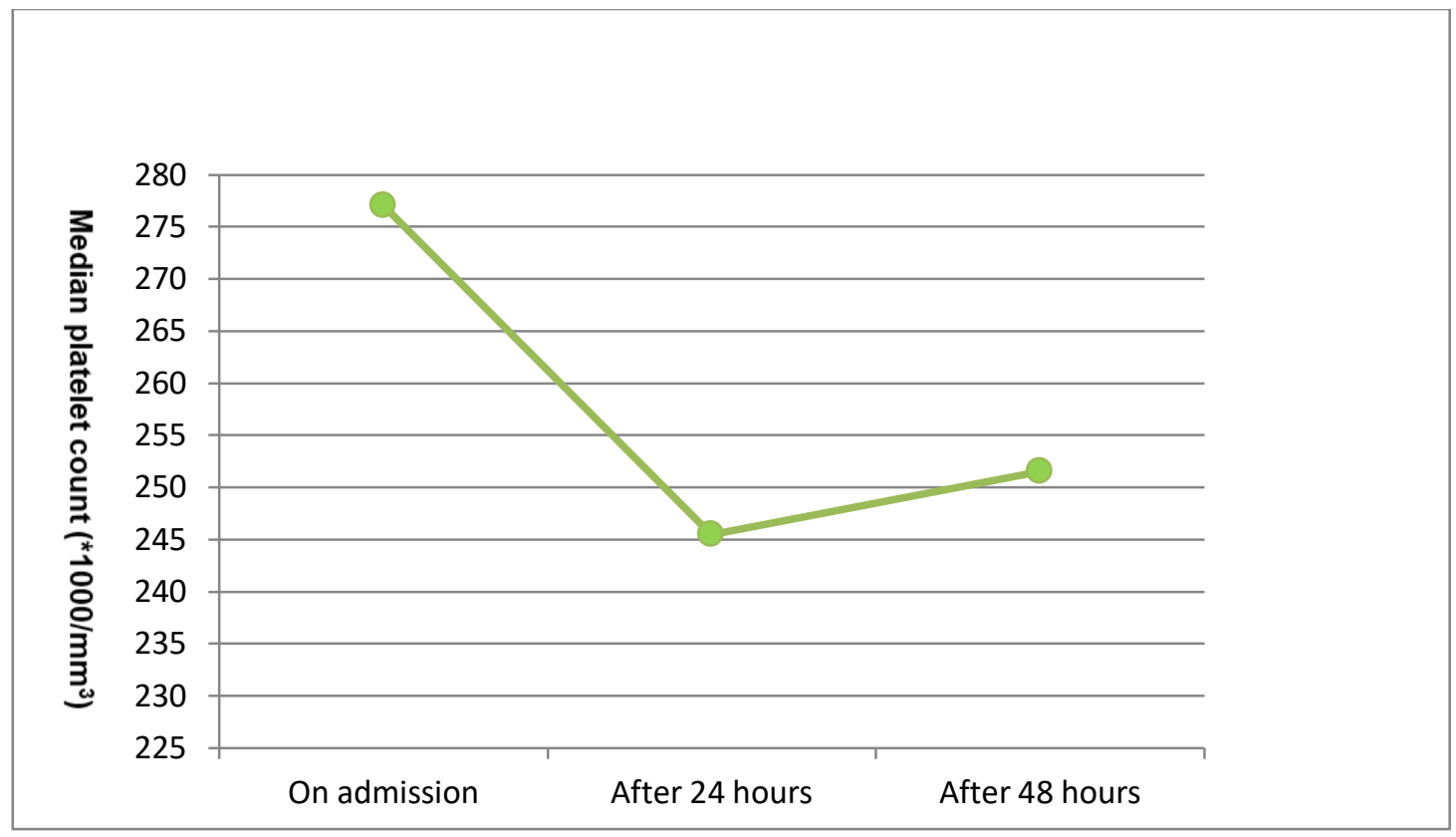

Fig (1) Line graph showing significant change in platelet count over time among the studied neonates.

Table (2) Change in platelet count over time in preterm neonates.

\begin{tabular}{|c|c|c|c|}
\hline Platelet count $\left(\times 1^{3} / \mathrm{mm}^{3}\right)$ & Pre & $n=36)$ & $\mathbf{P} *$ \\
\hline & Mean \pm SD & Median (range) & \\
\hline On admission & $242.74 \pm 78.69$ & $230(150-462)$ & -- \\
\hline After 24 hours & $206.97 \pm 71.28$ & $195(45-390)$ & 0.001 \\
\hline After 48 hours & $223.16 \pm 88.84$ & $206.5(67-421)$ & 0.001 \\
\hline Friedman test & \multirow{2}{*}{\multicolumn{2}{|c|}{$\begin{array}{c}48 \\
<0001\end{array}$}} & \\
\hline $\mathbf{P}$ & & & \\
\hline
\end{tabular}

*Wilcoxon signed rank test 


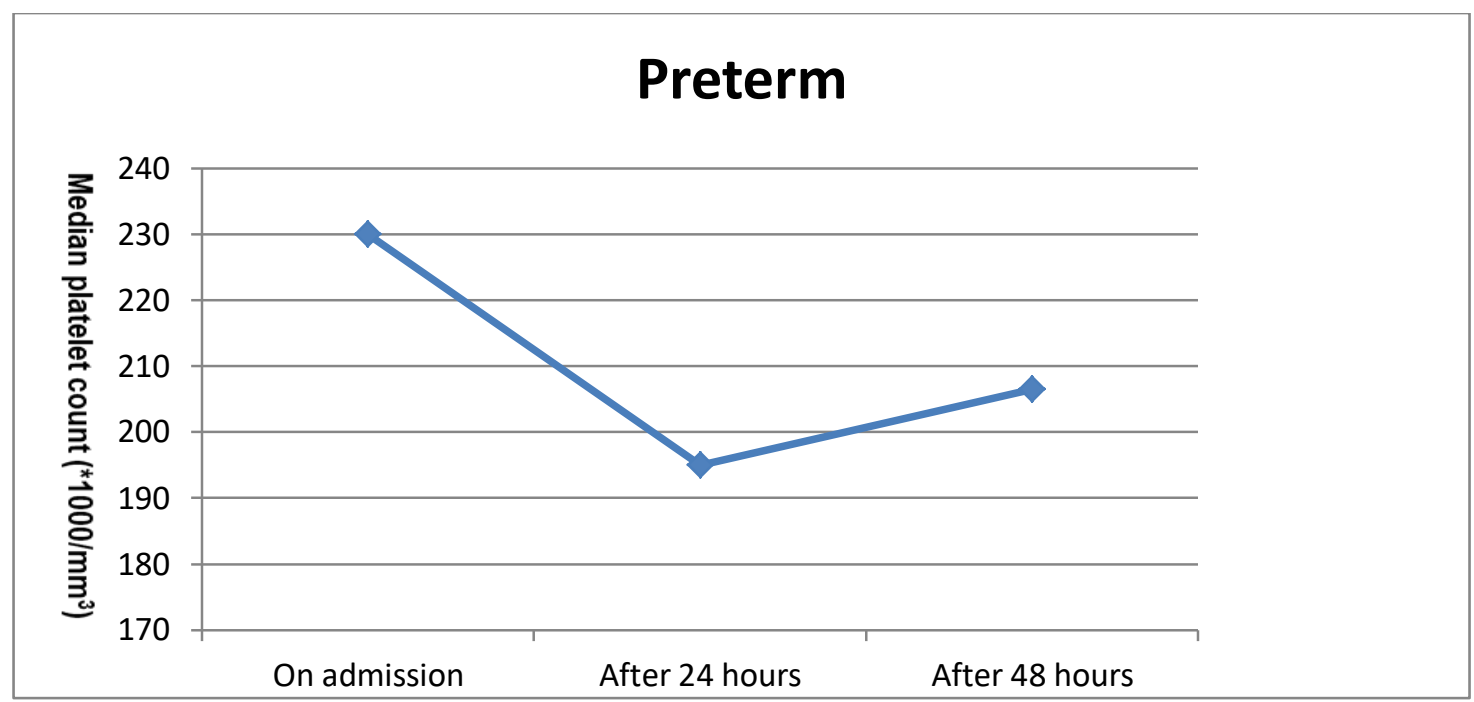

Fig (2) Line graph showing significant change in platelet count over time in preterm neonates.

Table (3) Change in platelet count over time in full term neonates.

\begin{tabular}{|c|c|c|c|}
\hline \multirow{2}{*}{ Platelet count $\left(\times ~ 10^{3} / \mathrm{mm}^{3}\right)$} & \multicolumn{2}{|c|}{ Full term $(n=64)$} & \multirow[t]{2}{*}{$\mathbf{P}^{*}$} \\
\hline & Mean \pm SD & Median (range) & \\
\hline On admission & $328.42 \pm 103.62$ & $300(158-451)$ & \\
\hline After 24 hours & $276.35 \pm 103.66$ & $280(87-479)$ & 0.001 \\
\hline After 48 hours & $287.08 \pm 116.83$ & $285(59-511)$ & 0.001 \\
\hline Friedman test & \multirow{2}{*}{\multicolumn{2}{|c|}{$\begin{array}{l}86.232 \\
<0.001\end{array}$}} & \\
\hline $\mathbf{P}$ & & & \\
\hline
\end{tabular}

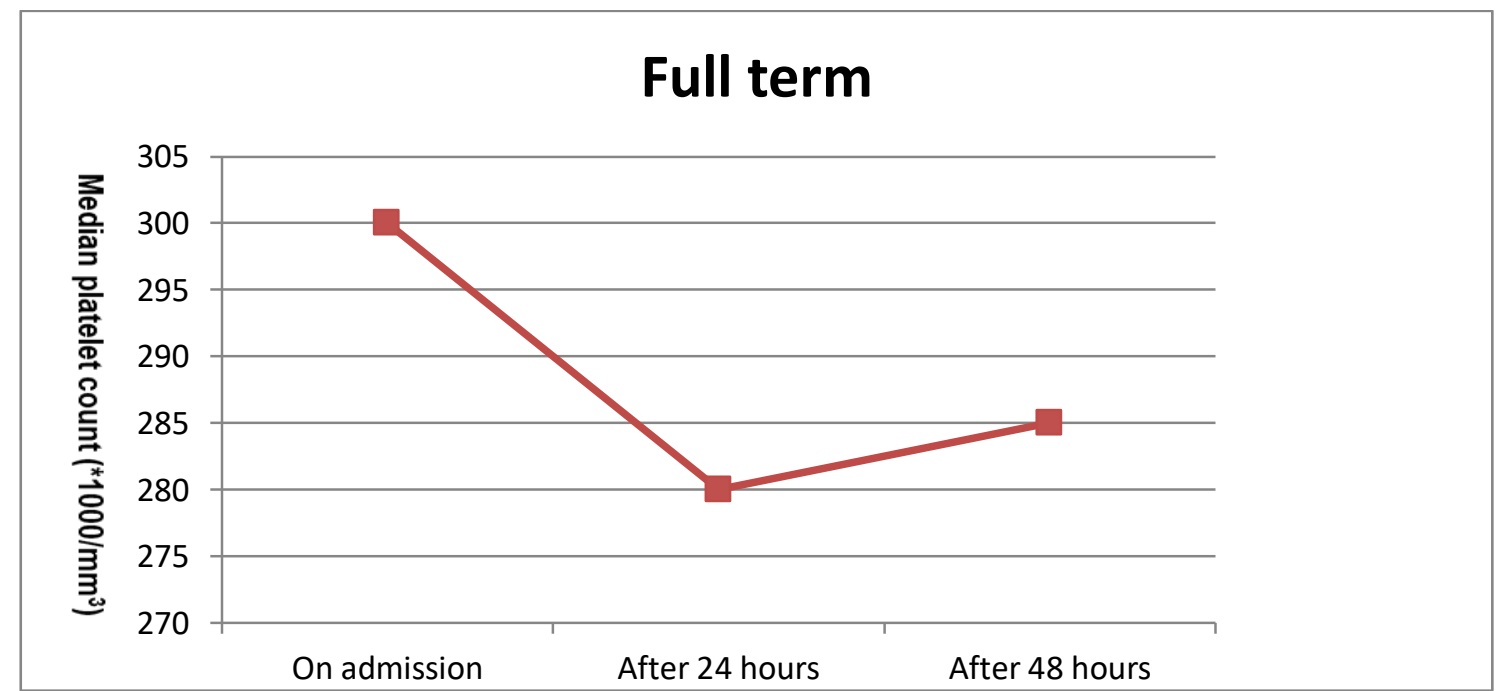

Fig (3) Line graph showing significant change in platelet count over time in full term neonates.

Table (4) Relation between gestational age and platelet count before and after phototherapy.

\begin{tabular}{lccccc}
\hline Platelet count & \multicolumn{2}{c}{ Preterm $(\mathbf{n = 3 6 )}$} & \multicolumn{2}{c}{ Full term $(\mathbf{n}=64)$} & \multirow{2}{*}{$\mathbf{P}^{*}$} \\
\cline { 2 - 5 }$\left(\mathbf{x ~} \mathbf{1 0}^{\mathbf{3}} / \mathbf{m m}^{\mathbf{3}}\right)$ & Mean \pm SD & Median (range) & Mean \pm SD & Median (range) & \\
\hline On admission & $242.74 \pm 78.69$ & $230(150-462)$ & $328.42 \pm 103.62$ & $300(158-451)$ & - \\
After 24 hours & $206.97 \pm 71.28$ & $195(45-390)$ & $276.35 \pm 103.66$ & $280(87-479)$ & 0.001 \\
After 48 hours & $223.16 \pm 88.84$ & $206.5(67-421)$ & $287.08 \pm 116.83$ & $285(59-511)$ & 0.001 \\
\hline
\end{tabular}

* Mann Whitney test. 


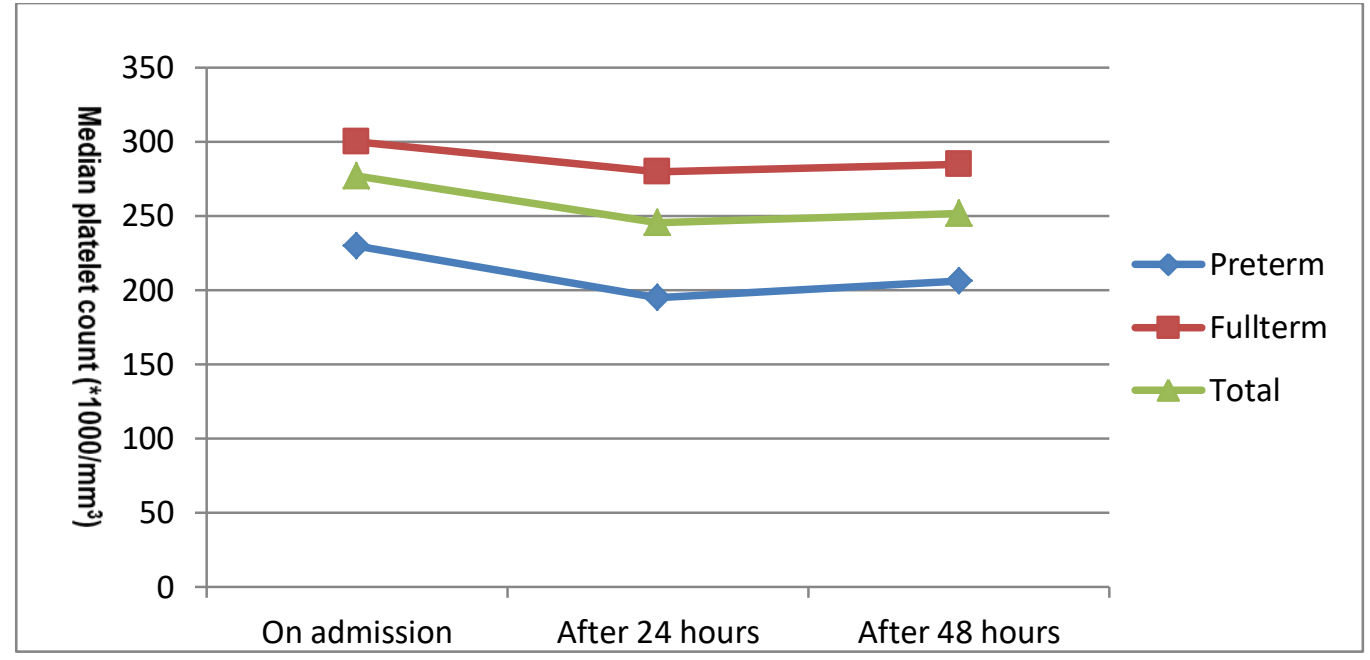

Fig (4) Comparison of platelet count during phototherapy.

Table (5) Relation between gender and platelet count before and after phototherapy.

\begin{tabular}{lccccc}
\hline Platelet count & \multicolumn{2}{c}{ Male $(\mathbf{N}=\mathbf{5 2})$} & \multicolumn{2}{c}{ Female $(\mathbf{N}=\mathbf{4 8})$} & \multirow{2}{*}{ P* } \\
\cline { 2 - 5 }$\left(\mathbf{x ~ 1 0} / \mathbf{m m}^{\mathbf{3}}\right)$ & Mean \pm SD & Median (range) & Mean \pm SD & Median (range) & \\
\hline On admission & $282.88 \pm 96.61$ & $268(151-523)$ & $309.92 \pm 109.43$ & $285.5(159-541)$ & 0.244 \\
After 24 hours & $239.73 \pm 94.56$ & $231.5(45-479)$ & $261.1 \pm 102.04$ & $249(96-450)$ & 0.425 \\
After 48 hours & $260.19 \pm 108.19$ & $252(59-486)$ & $265.6 \pm 115.15$ & $249(78-511)$ & 0.942 \\
\hline
\end{tabular}

* Mann Whitney test

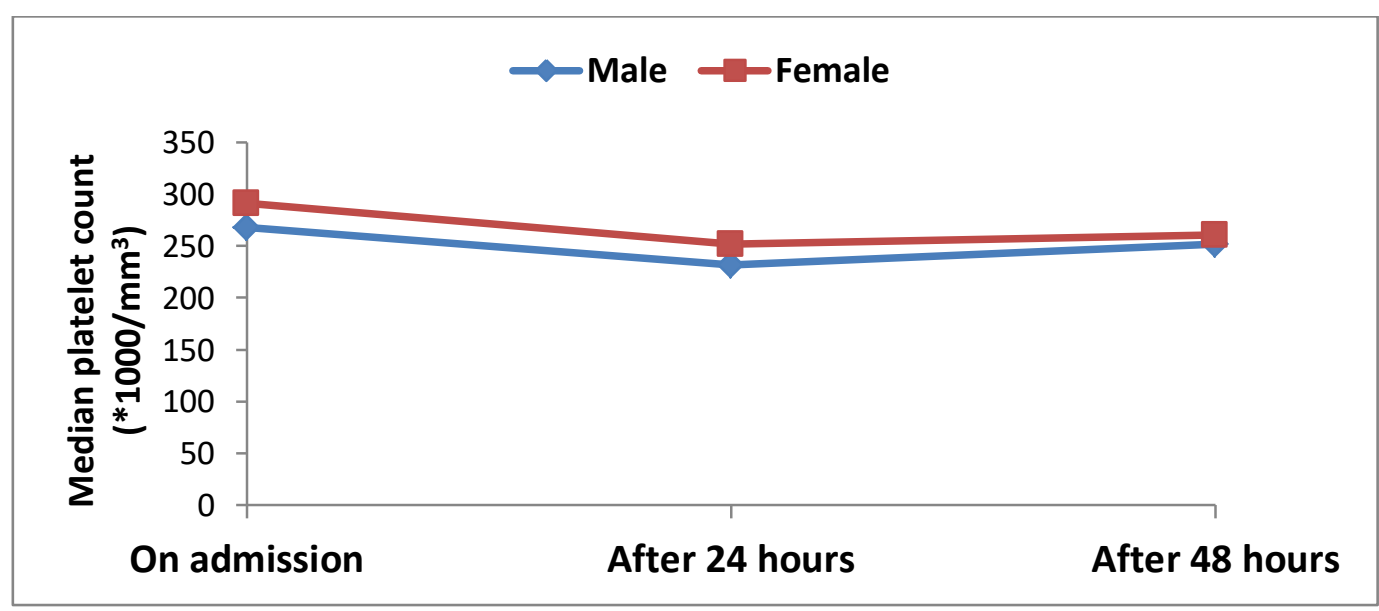

Fig (5) Line graph showing platelet count over time regarding gender.

Table (6) thrombocytopenia after phototherapy according to gestational age.

\begin{tabular}{lccc}
\hline Platelet count $\left(\mathbf{x} \mathbf{1 0}^{\mathbf{3}} / \mathbf{m m}^{\mathbf{3}}\right)$ & $\begin{array}{c}\text { Preterm } \\
\mathbf{N = 3 8}\end{array}$ & $\begin{array}{c}\text { Full term } \\
\mathbf{N = 6 2}\end{array}$ & $\begin{array}{c}\text { Total } \\
\mathbf{N = 1 0 0}\end{array}$ \\
\hline $\begin{array}{l}\text { At } \mathbf{2 4} \text { hr after phototherapy } \\
<\mathbf{1 5 0}\end{array}$ & $8(21 \%)$ & $11(17.7 \%)$ & $19(19 \%)$ \\
$>\mathbf{1 5 0}$ & $30(97 \%)$ & $51(82.3 \%)$ & $81(81 \%)$ \\
At $\mathbf{4 8}$ hr after phototherapy & & & \\
$<\mathbf{1 5 0}$ & $8(21 \%)$ & $15(24.2 \%)$ & $23(23 \%)$ \\
$>\mathbf{1 5 0}$ & $30(97 \%)$ & $47(75.8 \%)$ & $77(77 \%)$ \\
\hline
\end{tabular}


Table (7) Severity of thrombocytopenia after phototherapy according to gestational age.

\begin{tabular}{lccc}
\hline Platelet count $\left(\mathbf{x} \mathbf{1 0}^{\mathbf{3}} / \mathbf{m m}^{\mathbf{3}}\right)$ & Preterm & Full Term & Total \\
\hline At $\mathbf{2 4}$ hr after phototherapy & & & \\
$<\mathbf{5 0}$ (severe) & 1 & 0 & 0 \\
$\mathbf{5 1}-\mathbf{1 0 0}$ (moderate) & 1 & 2 & 4 \\
$\mathbf{1 0 1}-\mathbf{1 5 0}$ (mild) & 6 & 11 & 15 \\
Total & 8 & & 19 \\
At $\mathbf{4 8}$ hr after phototherapy & & 0 & \\
$<\mathbf{5 0}$ (severe) & 0 & 2 & 0 \\
$\mathbf{5 1}-\mathbf{1 0 0}$ (moderate) & 2 & 13 & 4 \\
$\mathbf{1 0 1}-\mathbf{1 5 0}$ (mild) & 6 & 15 & 19 \\
Total & 8 & & 23 \\
\hline
\end{tabular}

\section{Discussion}

In our examination, platelet include in preterm and full term neonates was essentially diminished after $24 \mathrm{~h}$ and $48 \mathrm{~h}$ of beginning phototherapy when contrasted and platelet depend on affirmation $(\mathrm{P}=0.001$ each), This is in accordance with [5] who found that the decline in platelet include was equivalent in both full term and preterm neonates. Then again, [6] and [7]

detailed that the abatement in platelet include was more in preterm than full term neonates. At the point when whole investigation populace was concentrated all in all, it was discovered that Platelet check was essentially diminished after $24 \mathrm{hrs}$ and $48 \mathrm{hrs}$ of beginning phototherapy when contrasted and platelet depend on affirmation ( $\mathrm{P}<0.001$ every), this is in predictable with Pishva et al. [5]

who contemplated the impact of phototherapy on platelets in 101 babies with backhanded hyperbilirubinemia and saw that 50/101 (49.5\%) had diminished platelet tally, Also, in Venaktamurthy et al. [8]

Study on 100 neonates in regards to phototherapy and its impact on platelet tally, they found a diminishing in mean platelet tally both on full-term and preterm neonates with factual criticalness on low birth weight neonates. This concurs with results by Sonwane et al. [6] and Mubashir et al. [7]

Who found that there was measurably noteworthy diminishing in platelet check after $24 \mathrm{~h}$ and $48 \mathrm{~h}$ of beginning phototherapy when contrasting and platelet tally before beginning phototherapy. The drop in platelets tally may be because of the photochemical response happens in the vascular bed and direct platelets injury by the bright light of phototherapy. This prompts decrease in platelets life range and an expansion in platelets turnover. Likewise, abbreviated platelet life range could be because of sequestration of harmed platelets in the spleen. Thrombocytopenia can likewise created when bone marrow remuneration is deficient .unexpectedly,. [9], [10], [11], [12] found that there was an expansion in the platelet tally after phototherapy. In our investigation, platelet tally at $24 \mathrm{~h}$ in the wake of beginning phototherapy was essentially diminished than
$48 \mathrm{~h}$ subsequent to beginning [5], [6] and [7] have revealed in their particular examinations that the decline in platelet tally $24 \mathrm{~h}$ following phototherapy is more than that $48 \mathrm{~h}$ following phototherapy yet it was of no factual importance $(\mathrm{P}=0.265)$. In this examination, $8(21 \%)$ of pre-term neonates and $11(17.7 \%)$ of full term neonates had thrombocytopenia (platelet check < $150 \times 103 / \mathrm{mm} 3$ ) after $24 \mathrm{~h}$ of beginning phototherapy. While, 8 (21\%) of preterm neonates and $15(24.2 \%)$ of full term neonates had thrombocytopenia after $48 \mathrm{~h}$ of beginning phototherapy. They were all clinically free.Also, the rate of thrombocytopenia was higher in preterm neonates $(21 \%)$ than that of full term neonates $(17.7 \%)$ at $24 \mathrm{~h}$ in the wake of gazing phototherapy, This is in accordance with [6] who found among their investigation populace; 23 patients had created thrombocytopenia $24 \mathrm{~h}$ after the phototherapy, $12(19.35 \%)$ were full term and 11 $(28.95 \%)$ were preterm. This likewise concurs with. [7] who announced a higher frequency of thrombocytopenia in preterm than full term neonates $(58.1 \%$ versus $36.7 \%)$ after $24 \mathrm{~h}$ of phototherapy But, [13] found that the rate of thrombocytopenia was more in full term than preterm neonates (86\% versus $14 \%)$ after $24 \mathrm{~h}$ of phototherapy.In our examination, the rate of thrombocytopenia after $48 \mathrm{~h}$ of phototherapy was higher in full term $(24.2 \%)$ than preterm neonates $(21 \%)$, This is in concurrence with [13] who found among their investigation populace; 35 patients had thrombocytopenia $48 \mathrm{~h}$ after phototherapy; $32(91 \%)$ full term and $3(8 \%)$ preterm neonates.On the opposite, [6] , [7] detailed higher occurrence of thrombocytopenia in preterm than full term neonates after $48 \mathrm{~h}$ of beginning phototherapy.In this examination, sexual orientation didn't show huge contrast in regards to platelet rely on confirmation, $24 \mathrm{~h}$ in the wake of beginning phototherapy $(\mathrm{P}=0.425)$ and $48 \mathrm{~h}$ in the wake of beginning phototherapy $(\mathrm{P}=0.942)$, This is in accordance with [13] [6] and [7] who announced in their separate investigations nonappearance of critical distinction dependent on sex in regards to platelet tally following phototherapy.

\section{Conclusion}

From the current study we could conclude that phototherapy in newborns with indirect 
hyperbilirubinemia leads to decrease in platelet count both in full term and preterm babies. The decrease in platelet count after phototherapy is transient. This decrease in platelet count is more significant after 24 hours of phototherapy.

\section{References}

[1] J. Rennie, B.R Shona, M. Maryam, Summary of NICE guidance. BMJ , Vol.340, PP. c2409,2010.

[2] L.A. Stokowski , Fundamentals of phototherapy for neonatal jaundice. Adv Neonatal care, Vol. 11(5 suppl), PP. s10-21,2011.

[3] T. Xiong, Y. Qu, S. Cambier ,The side effect of phototherapy for neonatal jaundice: what do we know? What should we do? Eur J Pediatr, Vol. 170, PP. 1247-1255, 2011.

[4] I. Roberts, S. Stanworth, N.A. Murray, Thrombocytopenia in the neonate. Blood Reviews, Vol. 22,PP. 173- 186, 2008.

[5] N. Pishva, H. Pishva, Incidence of thrombocytopenia in hyperbilirubinemic neonates during phototherapy. Acta Medica Iranica, Vol.38(1), PP. 7-9,2000.

[6] P. Sonawane, B. Bhaisara , A. Bhatawdekar, Effect of conventional phototherapy on platelet count in full-term and preterm neonates with indirect hyperbilirubinemia: A prospective cohort study. Journal of Medical Science and Clinical Research (JMSCR), Vol. 6(3), PP. 959-966,2018.

[7] H. Shah Mubashir, V. Ramya R. Reashma , Incidence of thrombocytopenia in neonates receiving phototherapy for indirect hyperbilirubinemia: a prospective cohort study. International Journal of Research in Medical Sciences Shah MH et al. Int J Res Med Sci, Vol. (9), PP.3505-3509,2019

[8] M. Venaktamurthy, M.D. Balaji, K.T. Reddy , A study on effect of phototherapy on platelet count in neonates with neonatal hyperbilirubinemia in a tertiary care rural hospital. Int J Contemp Pediatr, Vol. 3, PP. 253-5,2016

[9] H.D. Modanlou, O. Oritz, P.K. Wu , Lack of thrombocytopenia in newborn infants treated with phototherapy. Pediatric Research, Vol. 11, PP.538, 1977.

[10] K. Sakha , H. Sultani ,Effect of phototherapy on platelet and white blood cell count in term infants. Med J of Tabriz University of Medical Sciences, Vol. 28(3), PP. 14-8,2006.

[11] A. Monsef, F. Eghbalian , Does conventional phototherapy have any effect on platelet count in full term neonates with indirect hyperbilirubinemia. Sci Res, Vol. 3(12), PP. 709-11,2011.

[12] K.M. Ahmadpour, Y. Zahedpasha, M. Taghavi, Effect of phototherapy on platelet, reticulocyte and white blood cells in full term neonates with hyperbilirubinemia. Med J of Mashhad University of Medical Sciences. Wnter, Vol.55(4), PP. 2117,2013.

[13] M.K. Sanjeev, G. Col Rakesh , Incidence of thrombocytopenia following phototherapy in hyperbilirubinemic neonates. MJAFI, Vol.67(4), PP. 329-32, 2011. 